\title{
Forecasting Conditional Correlations in Stock, Bond and Foreign Exchange Markets
}

\author{
Hakim, A. ${ }^{1,2}$ and M. McAleer ${ }^{1}$ \\ ${ }^{1}$ School of Economics and Commerce, University of Western Australia \\ ${ }^{2}$ Faculty of Economics, Islamic University of Indonesia. \\ Email: hakima01@student.uwa.edu.au
} Keywords: Conditional correlation, Forecasting, Rolling window, CCC, VARMA-AGARCH, VARMA-
GARCH.

\section{EXTENDED ABSTRACT}

Unlike conditional volatility that has been investigated intensively, conditional correlations between financial assets have received only little attention in literature. Researchers have, for so long, focused mainly on estimating returns and risk, and have assumed that the correlations are constant and have therefore paid less attention on them. However, recent studies uncover that such correlations vary over time. Therefore, modelling and forecasting future correlations between financial assets become a need. The paper fills the gap by forecasting conditional correlations between three classes of international financial assets, namely stock, bond and foreign exchange, considering the importance of those assets in portfolio construction.

Diversification of portfolios across countries offers smaller correlations of expected returns than within a country for two reasons: (1) the economy and political environment evolve differently across countries, and (2) countries have different industries in their stock market indices (see Heston and Rouwenhost (1994)). Even though there is little evidence that either stock or bond markets have become more volatile worldwide, correlations appear to increase when market volatility increases (Odier and Solnik (1993)). As volatility spillovers and asymmetric effects of negative and positive shocks on conditional variance are evident to be the sources of volatilities in financial assets, it is imperative to investigate whether models that incorporate such specifications provide better conditional correlation forecasts.

Two countries are considered, namely Australia and New Zealand. Both countries have strong economy relationship, hence return and volatility spillovers are expected to occur across both markets. In addition, both countries are of the same time zone. This avoids the problem of nonsynchronous data.
Forecasting will be conducted using three multivariate GARCH models, namely the Constant Conditional Correlation (CCC) model of Bollerslev (1990), VARMA-GARCH model of Ling and McAleer (2003), and VARMAAGARCH model of Chan et al. (2002). A rolling window is used to forecast 1-day ahead conditional correlations. To evaluate the impact of model specification on conditional correlation forecasts, this paper calculates and compares the correlations between conditional correlation forecasts.

Forecasting correlations between stock, bond and foreign exchange have been undertaken by several papers using various models. Unlike most papers in literature that compare conditional forecasts with realized volatility in order to test the accuracy of such models, this paper is intended to analyze whether multivariate GARCH models incorporating volatility spillovers and asymmetric effect of negative and positive shocks on conditional variance provide better conditional correlation forecasts.

The data used in this paper are the daily closing price index of stock, bond and foreign exchange rates from Australia and New Zealand. The stock indices are S\&P ASX 200 Price Index and NZX ALL Price Index, while the bond indices are AU Benchmark 10 Year Govt. Index and NZ Benchmark 10 Year Govt. Index. Both foreign exchange rates are against US dollar. With stock, bond, and foreign exchange rates of both countries, there are 6 series of assets to be analyzed. This constructs 15 bivariate models to be estimated.

The paper suggests that incorporating volatility spillovers and asymmetric of negative and positive shocks on conditional variance do not contribute to better conditional correlation forecasts. 


\section{INTRODUCTION}

Three key elements in portfolio construction are estimates of returns, risks and correlations of assets in the portfolio. Researchers have, for so long, focused mainly on estimating returns and risk, and have assumed that correlations are constant and have therefore paid less attention on them. However, recent studies uncover that the correlations vary over time (see De Santis and Gerard (1998) and Longin and Solnik (2001) for stock, Hunter and Simon (2005) and Solnik et al. (1996) for bonds). Therefore, modeling and forecasting future correlation between assets becomes a need. A forecast of correlation between two financial asset prices is required to price or hedge an option whose payoff depends on both assets prices or to measure the risk of a portfolio whose return depends on both asset prices (Gibson (1998)).

The paper forecasts conditional correlations between financial assets using three multivariate GARCH models, namely the CCC, VARMAAGARCH and VARMA-GARCH models. Three classes of assets are included in the models, namely stock, bond and foreign exchange, considering the importance of those assets in portfolio construction (see Chen, Roll, and Ross (1986) and Odier and Solnik (1993), among others). Two countries are considered, namely Australia and New Zealand. Both countries have strong economy relationships, hence volatility spillovers are expected to occur across both markets. In addition, both countries are of the same time zone. This avoids the problem of nonsynchronous data.

A rolling window is used to forecast 1-day ahead conditional correlations. To evaluate the impact of model specification on the forecast of conditional correlations, the paper calculates and compares the correlation between the forecast of conditional correlations.

\section{LITERATURE REVIEW}

Forecasting correlations between stock, bond and foreign exchange have been undertaken by several papers using various models. Various tests have been used to evaluate the forecasts accuracy. Forecasting correlations between international stocks has been undertaken by McAleer and da Veiga (2007) using the CCC, VARMA-GARCH, and a new proposed model, the Portfolio Spillover (PS)-GARCH. A rolling window approach is used to forecast 1-day ahead conditional correlations. To compare the forecast accuracy, they calculate the correlation between conditional correlation forecasts. They find that all three models yield very similar results.

Wainscott (1990) uses historical rolling correlation to forecast future correlations between stock and bond. To test the accuracy of the forecasts, he calculates the correlation between the conditional correlation forecasts and the following period non-overlapping correlation. He suggests that historical correlation is an unsatisfactory predictor of future correlation.

Campa and Chang (1998) use implied, historical, RiskMetrics's Moving Average, and bivariate GARCH based correlation to forecast the correlation between exchange rates. The forecasts are evaluated by computing Root Mean Squared Error for the alternative forecasts, regress the realized correlation individually against each of the alternative forecasts, and 'encompassing regressions' in which two or more alternative forecasts are included as regressors. They suggest that implied correlation forecast is superior to the others.

Unlike the previous papers, this paper is not intended to evaluate forecasts accuracy of models. Its main goal is to analyze whether multivariate GARCH models incorporating volatility spillovers and asymmetric effect of negative and positive shocks on conditional variance provide better conditional correlation forecasts. The CCC model is the benchmark model as it does not incorporate volatility spillovers and asymmetric effects of negative and positive effects on conditional variance. The models that consider volatility spillovers are the VARMA-AGARCH and VARMA-GARCH models. Asymmetric effect of negative and positive shock on conditional variance is incorporated in VARMAAGARCH model.

\section{METHODS}

This section briefly discusses the estimated models. Consider the following model specification:

$$
\begin{aligned}
& y_{t}=E\left(y_{t} \mid F_{t-1}\right)+\varepsilon_{t} \\
& \varepsilon_{t}=D_{t} \eta_{t},
\end{aligned}
$$

where $y_{t}=\left(y_{1 t}, \ldots, y_{m t}\right)^{\prime}, \quad \eta_{t}=\left(\eta_{1 t}, \ldots, \eta_{m t}\right)^{\prime}$ is a sequence of independently and identically distributed (iid) random vectors, and $D_{t}=\operatorname{diag}\left(h_{1 t}^{1 / 2}, \ldots, h_{m t}^{1 / 2}\right)$. Bollerslev (1990) assumes the conditional variance for each asset, 
$h_{i t}, i=1, \ldots, m$, follows a univariate GARCH process, that is,

$h_{i t}=\omega_{i}+\sum_{j=1}^{r} \alpha_{i j} \varepsilon_{i, t-j}^{2} \sum_{j=1}^{s} \beta_{i j} h_{i, t-j}$,

where $\alpha_{i j}$ represents the ARCH effects and $\beta_{i j}$ represents the GARCH effects.

This model assumes independence of the conditional variance across countries. In order to accommodate possible interdependencies, Ling and McAleer (2003) proposed the following specification for the conditional variance:

$H_{t}=W+\sum_{i=1}^{r} A_{i} \vec{\varepsilon}_{t-i}+\sum_{j=1}^{s} B_{j} H_{t-j}$

where $H_{t}=\left(h_{1 t}, \ldots, h_{m t}\right)^{\prime}, \quad \vec{\varepsilon}_{t}=\left(\varepsilon_{1 t}^{2}, \ldots, \varepsilon_{m t}^{2}\right)^{\prime}$, and $W, A_{i} \forall i=1, \ldots, r$ and $B_{j} \forall j=1, \ldots, s$ are $m \times m$ matrices. VARMA-GARCH assumes that negative and positive shocks have identical impacts on the conditional variance. In order to accommodate asymmetric impacts of positive and negative shocks, Chan, Hoti and McAleer (2002) proposed the following specification of conditional variance.

$H_{t}=W+\sum_{i=1}^{r} A_{i} \vec{\varepsilon}_{t-i}+\sum_{l=1}^{r} C_{i} I_{t-i} \vec{\varepsilon}_{t-i}+\sum_{j=1}^{s} B_{j} H_{t-j}$

where $C_{i}$ are $m x m$ matrices for $i=1, \ldots, r$ and $I_{t}=\operatorname{diag}\left(I_{1 t}, \ldots, I_{m t}\right)$, so that

$I=\left\{\begin{array}{l}0, \varepsilon_{i, t}>0 \\ 1, \varepsilon_{i, t} \leq 0\end{array}\right.$.

VARMA-AGARCH reduces to VARMAGARCH when $C_{i}=0$ for all $i$. Furthermore, if $C_{i}=0$, with $A_{i}$ and $B_{i}$ being diagonal matrices for all $i, j$, then VARMA-AGARCH reduces to CCC, and both VARMA-GARCH and CCC nested to VARMA-AGARCH.

The structural and statistical properties of VARMA-GARCH were established in Ling and McAleer (2003). This includes the necessary and sufficient conditions for stationary and ergodicity, sufficient conditions for the existence of moments of $\varepsilon_{t}$, and sufficient conditions for consistency and asymptotic normality of the Quasi-Maximum Likelihood Estimator in the absence of normality of $\eta_{t}$. As CCC is nested within VARMAGARCH, the structural and statistical properties established in Ling and McAleer (2003) also apply to CCC.

The structural and statistical properties of VARMA-AGARCH were established in Chan, Hoti and McAleer (2002). As an extension of VARMA-GARCH, it follows that the conditions established for VARMA-AGARCH are equivalent to those for VARMA-GARCH when $C_{i}=0$ for all $i$.

The conditional correlation is assumed to be constant for all the models. From (2), it is obvious that

$\varepsilon_{t} \varepsilon_{t}^{\prime}=D_{t} \eta_{t} \eta_{t}^{\prime} D_{t}$

and, as $\eta_{t}$ is a sequence of iid random vectors, the conditional covariance matrix is

$E\left(\varepsilon_{t} \varepsilon_{t}^{\prime} \mid F_{t-1}\right)=\Omega_{t}=D_{t} \Gamma D_{t}$,

where $\Gamma=E\left(\varepsilon_{t} \varepsilon_{t}^{\prime} \mid F_{t-1}\right)=E\left(\eta_{t} \eta_{t}^{\prime}\right)$, which is a constant matrix for all $t$. The conditional correlation matrix is then defined as

$\Gamma=D_{t}^{-1} \Omega_{t} D_{t}^{-1}$,

which is assumed to be constant over time. Furthermore, the conditional correlation of $\varepsilon_{t}$ is, by definition, equal to the covariance matrix of the standardized shocks, $\eta_{t}$.

It should be noted as well that restricting the model given in equation (5) so that the matrices $A_{l}, B_{l}$ and $C_{l}$ are diagonal, the VARMAAGARCH model reduces to the univariate GJR model proposed by Glosten, Jagannathan and Runkle (1993), as follows:

$h_{i t}=\omega_{i}+\sum_{l=1}^{r}\left(\alpha_{i} \varepsilon_{i, t-l}^{2}+\gamma_{i} I_{i, t-l} \varepsilon_{i, t-1}^{2}\right)+\sum_{l=1}^{s} \beta_{i} h_{i, t-l}$

\section{DATA ANALYSIS}

The data used in the paper are the daily closing price index of stock, bond and foreign exchange rates from Australia and New Zealand. The stock indices are S\&P ASX 200 Price Index and NZX ALL Price Index, while the bond indices are AU Benchmark 10 Year Govt. Index and NZ 
Benchmark 10 Year Govt. Index. Both foreign exchange rates are against US dollar.

All data are obtained from the DataStream database services. The sample ranges from $5 / 5 / 1997$ to $2 / 5 / 2007$, with 2,608 observations for each asset. Returns of market $i$ at time $t$ are calculated as $R_{i, t}=100 \times \log \left(P_{i, t} / P_{i, t-1}\right)$, where $P_{i, t}$ and $P_{i, t-1}$ are the closing prices of asset $i$ for days $t$ and $t-1$, respectively. All returns are found to be stationary, based on both ADF and Phillips-Perron tests.

In order to see whether conditional variances of the assets follow the ARCH process, univariate ARMA-GARCH and ARMA-GJR models will be estimated. Univariate ARMA-GARCH nested to VARMA-GARCH, with conditional variance specified in (3). Univariate GJR nested to VARMA-AGARCH with conditional variance specified in (9). If the properties of univariate models are satisfied, then it would be sensible to extend the models to their multivariate counterparts.

Table 1. Univariate ARMA-GARCH

\begin{tabular}{|l|c|c|c|c|c|c|}
\hline & \multicolumn{3}{|c|}{ Mean Equation } & \multicolumn{3}{c|}{ Variance Equation } \\
\hline & $\mathrm{C}$ & $\mathrm{AR}(1)$ & $\mathrm{MA}(1)$ & $\omega$ & $\alpha$ & $\beta$ \\
\hline Ausbond & 0.01 & -0.11 & 0.11 & $\mathbf{0 . 0 0}$ & $\mathbf{0 . 0 3}$ & $\mathbf{0 . 9 6}$ \\
\hline Nzbond & 0.01 & 0.10 & -0.08 & $\mathbf{0 . 0 2}$ & $\mathbf{0 . 0 4}$ & $\mathbf{0 . 9 4}$ \\
\hline Ausstock & $\mathbf{0 . 0 7}$ & -0.43 & $\mathbf{0 . 4 9}$ & $\mathbf{0 . 0 6}$ & $\mathbf{0 . 0 7}$ & $\mathbf{0 . 8 8}$ \\
\hline Nzstock & $\mathbf{0 . 0 6}$ & $\mathbf{0 . 9 0}$ & $\mathbf{- 0 . 8 9}$ & $\mathbf{0 . 0 6}$ & $\mathbf{0 . 1 0}$ & $\mathbf{0 . 8 6}$ \\
\hline Usdaud & -0.02 & $\mathbf{0 . 9 9}$ & $\mathbf{- 0 . 9 9}$ & $\mathbf{0 . 0 1}$ & $\mathbf{0 . 0 4}$ & $\mathbf{0 . 9 5}$ \\
\hline Usdnzd & -0.01 & 0.42 & -0.43 & $\mathbf{0 . 0 2}$ & $\mathbf{0 . 0 5}$ & $\mathbf{0 . 9 0}$ \\
\hline
\end{tabular}

Table 2. Univariate ARMA-GJR

\begin{tabular}{|l|c|c|c|c|r|r|r|}
\hline & \multicolumn{3}{|c|}{ Mean Equation } & \multicolumn{4}{c|}{ Variance Equation } \\
\hline & C & AR(1) & MA(1) & $\omega$ & $\alpha$ & $\gamma$ & $\beta$ \\
\hline Ausbond & 0.00 & 0.59 & -0.62 & $\mathbf{0 . 0 0}$ & 0.02 & $\mathbf{0 . 0 2}$ & $\mathbf{0 . 9 7}$ \\
\hline Nzbond & 0.00 & -0.33 & 0.35 & $\mathbf{0 . 0 3}$ & 0.02 & $\mathbf{0 . 0 6}$ & $\mathbf{0 . 9 1}$ \\
\hline Ausstock & $\mathbf{0 . 0 5}$ & -0.37 & 0.41 & $\mathbf{0 . 0 7}$ & -0.01 & $\mathbf{0 . 1 3}$ & $\mathbf{0 . 8 8}$ \\
\hline Nzstock & 0.04 & -0.14 & 0.18 & 0.10 & $\mathbf{0 . 0 5}$ & $\mathbf{0 . 1 3}$ & $\mathbf{0 . 8 1}$ \\
\hline Usdaud & -0.02 & $\mathbf{1 . 0 0}$ & $\mathbf{- 1 . 0 0}$ & $\mathbf{0 . 0 1}$ & $\mathbf{0 . 0 6}$ & -0.02 & $\mathbf{0 . 9 4}$ \\
\hline Usdnzd & -0.01 & 0.47 & -0.49 & $\mathbf{0 . 0 3}$ & $\mathbf{0 . 0 8}$ & $\mathbf{- 0 . 0 5}$ & $\mathbf{0 . 9 0}$ \\
\hline
\end{tabular}

Table 3. Second and log moment conditions

\begin{tabular}{|l|c|c|c|c|}
\hline \multirow{2}{*}{} & \multicolumn{2}{|c|}{ ARMA-GARCH } & \multicolumn{2}{c|}{ ARMA-GJR } \\
\cline { 2 - 5 } & $\begin{array}{c}\text { Second } \\
\text { Moment }\end{array}$ & $\begin{array}{c}\text { Log } \\
\text { Moment }\end{array}$ & $\begin{array}{c}\text { Second } \\
\text { Moment }\end{array}$ & $\begin{array}{c}\text { Log } \\
\text { Moment }\end{array}$ \\
\hline Ausbond & 0.99 & -0.01 & 0.99 & -0.01 \\
\hline Nzbond & 0.98 & -0.03 & 0.95 & -0.05 \\
\hline Ausstock & 0.95 & -0.05 & 0.93 & -0.08 \\
\hline Nzstock & 0.96 & -0.06 & 0.93 & -0.10 \\
\hline Usdaud & 0.99 & -0.01 & 0.98 & -0.02 \\
\hline Usdnzd & 0.96 & -0.05 & 0.95 & -0.06 \\
\hline
\end{tabular}

From Tables 1 and 2, coefficients in mean equations are not all significant. This can be interpreted as the behaviour of those returns is possibly also determined by other variables such as returns spillovers from other markets. Coefficients in conditional variance equations from both models show that most series are influenced by GARCH effects, even though some are not influenced by ARCH effects. In addition, most series show the asymmetric effect of negative and positive shock on conditional variance.

In order to check structural properties of both univariate models, second moment conditions and log-moments are evaluated for both models. Ling and McAleer (2003) showed that quasi maximum likelihood estimators (QMLE) for $\operatorname{GARCH}(r, s)$ is consistent if second moment regularity condition is finite. Jeantheau (1988) showed that logmoment regularity condition given by $E\left(\log \left(\alpha_{1} \eta_{t}^{2}+\beta_{1}\right)\right)<0$, is sufficient for QMLE to consistent for the GARCH model. The second moment condition, namely $\alpha_{1}+\frac{\gamma_{1}}{2}+\beta_{1}<1$, is sufficient for consistency and asymptotic normality of the QMLE for GJR. Moreover, McAleer et al. (2002) established the log-moment regularity condition for the GJR model, $E\left(\log \left(\left(\alpha_{1}+\gamma_{1} I\left(\eta_{t}\right)\right) \eta_{t}^{2}+\beta_{1}\right)\right)<0$, and showed that it is sufficient for the consistency and asymptotic normality of the QMLE for GJR. Table 3 shows that both log-moment and second moment conditions for both models are satisfied for all returns.

\section{ESTIMATION AND FORECAST}

The purpose of this section is to compare the conditional correlation forecasts based on CCC, VARMA-AGARCH and VARMA-GARCH models. A rolling window approach is used to forecast 1-day ahead conditional correlations. The sample ranges from $5 / 5 / 1997$ to $2 / 5 / 2007$. In order strike the balance between efficiency in estimation and a viable number or rolling regression, the rolling window size is at 2000 for all data set, which leads to a forecasting period from $3 / 1 / 2005-2 / 5 / 2007$. With stock, bond, and foreign exchange rates of both countries, there are 6 series of assets to be analyzed. This constructs 15 bivariate models to be estimated.

The conditional correlation forecasts are depicted in Figures 1 to 15. It is clear that the conditional correlation forecasts are not constant. In addition to the fluctuating correlations, the correlations between stock and bond exhibit upward trend, while that of between stock and exchange exhibit downward trend. 
The correlation between conditional correlation forecasts resulted from the three models are shown in Table 4. The evidence of volatility spillovers and asymmetric effects are reported in Table 5.

Table 4. Correlation between forecasts of conditional correlation resulted from each model.

\begin{tabular}{|r|l|c|c|c|}
\hline \multirow{2}{*}{ No } & \multirow{2}{*}{ Paiars of Assets } & \multicolumn{3}{|c|}{ Correlations } \\
\cline { 3 - 5 } & & $1-2$ & $1-3$ & $2-3$ \\
\hline 1 & Ausbond-Nzbond & 0.97 & 0.98 & 0.98 \\
\hline 2 & Ausbond-Ausstock & 0.91 & $\mathbf{0 . 8 9}$ & $\mathbf{0 . 8 3}$ \\
\hline 3 & Ausbond-Nzstock & 0.98 & $\mathbf{0 . 8 7}$ & $\mathbf{0 . 8 4}$ \\
\hline 4 & Ausbond-Usdaud & 0.92 & 0.97 & 0.95 \\
\hline 5 & Ausbond-Usdnzd & $\mathbf{0 . 8 6}$ & $\mathbf{0 . 8 4}$ & $\mathbf{0 . 8 5}$ \\
\hline 6 & Nzbond-Ausstock & $\mathbf{0 . 8 2}$ & 0.95 & $\mathbf{0 . 7 6}$ \\
\hline 7 & Nzbond-Nzstock & 0.99 & 0.99 & 0.99 \\
\hline 8 & Nzbond-Usdaud & 0.98 & 0.99 & 0.98 \\
\hline 9 & Nzbond-Usdnzd & 0.98 & 0.99 & 0.98 \\
\hline 10 & Ausstock-Nzstock & 0.98 & 0.99 & 0.97 \\
\hline 11 & Ausstock-Usdaud & 0.95 & 0.96 & 0.93 \\
\hline 12 & Ausstock-Usdnzd & 0.97 & 0.99 & 0.97 \\
\hline 13 & Nzstock-Usdaud & 0.99 & 0.99 & 0.99 \\
\hline 14 & Nzstock-Usdnzd & 0.99 & 0.99 & 0.99 \\
\hline 15 & Usdaud-Usdnzd & 0.99 & 0.99 & 0.99 \\
\hline
\end{tabular}

Notes:

- 1 = CCC, 2 = VARMA-AGARCH, and 3 = VARMAGARCH.

- Entries in bold are considered as low correlation coefficients.

Table 5. Summary of volatility spillovers and asymmetric effect of negative and positive shocks

\begin{tabular}{|r|l|c|c|c|}
\hline \multirow{2}{*}{ No } & & \multicolumn{2}{|c|}{$\begin{array}{c}\text { Number of } \\
\text { Volatility Spillovers }\end{array}$} & $\begin{array}{c}\text { Number of } \\
\text { Asymmetric } \\
\end{array}$ \\
\cline { 3 - 4 } & & $\begin{array}{c}\text { VARMA- } \\
\text { AGARCH }\end{array}$ & $\begin{array}{c}\text { VARMA } \\
\text {-GARCH }\end{array}$ & \\
\hline 1 & Ausbond-Nzbond & 1 & 1 & 2 \\
\hline 2 & Ausbond-Ausstock & 0 & 0 & 2 \\
\hline 3 & Ausbond-Nzstock & 0 & 0 & 1 \\
\hline 4 & Ausbond-Usdaud & 2 & 1 & 2 \\
\hline 5 & Ausbond-Usdnzd & 0 & 0 & 1 \\
\hline 6 & Nzbond-Ausstock & 2 & 1 & 2 \\
\hline 7 & Nzbond-Nzstock & 0 & 0 & 1 \\
\hline 8 & Nzbond-Usdaud & 2 & 1 & 1 \\
\hline 9 & Nzbond-Usdnzd & 1 & 2 & 2 \\
\hline 10 & Ausstock-Nzstock & 1 & 0 & 2 \\
\hline 11 & Ausstock-Usdaud & 1 & 2 & 2 \\
\hline 12 & Ausstock-Usdnzd & 0 & 0 & 2 \\
\hline 13 & Nzstock-Usdaud & 1 & 1 & 1 \\
\hline 14 & Nzstock-Usdnzd & 0 & 0 & 2 \\
\hline 15 & Usdaud-Usdnzd & 2 & 2 & 1 \\
\hline
\end{tabular}

As volatility spillovers are evident not in all cases, it might be interesting to find out whether they have any connection to the forecasts of conditional correlations. There are two cases where the correlations between CCC and
VARMA-AGARCH are low (less than 0.9$)^{*}$. One of them occurs when the volatility spillovers are evident (Nzbond-Ausstock). However, the other case (Ausbond-Usdnzd) occurs even when the volatility spillovers are not evident. Furthermore, in most cases where volatility spillovers are evident, the correlation between CCC and VARMA-AGARCH remains high. This suggests that volatility spillovers do not contribute to better conditional correlation forecasts. Additional evidence that support this suggestion is provided by the correlations between the forecasts of CCC and VARMA-GARCH. Two cases of low correlations (Ausbond-Nzstock and AusbondUsdnzd) occur even when volatility spillovers are not evident.

As shown in Table 4, the correlations between the conditional correlation forecasts of the three models are high in most cases (0.95 on average). Even though asymmetric effects are evident in all cases, the correlation between conditional correlation forecasts of CCC and VARMAAGARCH and that of between VARMAAGARCH and VARMA-GARCH are as high as that of between CCC and VARMA-GARCH. This suggests that asymmetric effects do not have any significant impact on the conditional correlation forecasts.

\section{CONCLUSION}

The paper compared conditional correlation forecasts resulted from the CCC, VARMAAGARCH and VARMA-GARCH models. A rolling window approach was used to forecast 1day ahead conditional correlations. Evaluation was conducted by analyzing the correlation of conditional correlation forecasts resulted from the models, along with the evidence of volatility spillovers and asymmetric effect of negative and positive shocks on conditional variance.

The paper suggested that incorporating volatility spillovers and asymmetric of negative and positive shocks on conditional variance does not affect forecasting conditional correlation.

\footnotetext{
* As Cohen et al. (1988) note, there is no formal interpretation of correlation size, it depends on the context and purposes. This paper assumes 0.9 as low correlation coefficient since it expects that those models will yield similar correlation forecasts, as the CCC and VARMA-GARCH models nested to VARMA-AGARCH model.
} 


\section{REFERENCES}

Bollerslev, T. (1990), Modelling the coherence in short-run nominal exchange rates: a multivariate generalized ARCH model, Review of Economics and Statistics, 72, 498-505

Campa, J.M. and P.H.K. Chang (1998), The forecasting ability of correlations implied in foreign exchange options, Journal of International Money and Finance, 17, 855-880.

Chan, F., M. McAleer, and S. Hoti (2002), Structure and asymptotic theory for multivariate asymmetric volatility: empirical evidence for country risk ratings, Invited paper presented to the Australasian Meeting of the Econometric Society, Brisbane, Australia, July 2002.

Chen, N.F., R. Roll and S.A. Ross (1986), Economic forces and the stock markets, Journal of Business, 59, 383-403.

Chou, R.Y. (2004), Forecasting financial volatilities with extreme values: the conditional autoregressive range (CARR) model, Journal of Money Credit and Banking, forthcoming.

Cohen, J., P. Cohen, S.G. West and L.S. Aiken (2003), Applied multiple regression/ correlation analysis for the behavioral sciences, $\left(3^{\text {rd }}\right.$ edition) Hillsdale, $\mathrm{NJ}$ : Lawrence Erlbaum Associeates.

Gibson, M.S. and B.H. Boyer (1998), Evaluating forecasts of correlation using option pricing, Board of Governor of the Federal Reserve System, International Finance Discussion Paper Number 600, September.

Glosten, L.R., R. Jagannathan, and D. Runkle (1993), On the relation between the expected value and the volatility of the normal excess return on stocks, Journal of Finance, 48, 1779-1801.

Heston, S.L. and K.G. Rouwenhorst (1994), Does industrial structure explain the benefits of international diversification, Journal of Financial Economics, 3-27.

Hunter, D.M. and D.P. Simon (2005), A conditional assessment of the relationships between the major world bond markets,
European Financial Management, 11(4), 463-482.

Jeantheau, T. (1998), Strong consistency of estimators for multivariate ARCH models, Econometric Theory, 14, 70-86.

Ling, S. and M. McAleer (2003), Asymptotic theory for a vector ARMA-GARCH model, Econometric Theory, 19(2), 280310.

Longin, F. and B. Solnik (2001), Extreme correlation of international equity markets, Journal of Finance, LVI(2), 646-676.

McAleer, M., F. Chan, and D. Marinova, 2002, An econometric analysis of asymmetric volatility: theory and application to patents, to appear in Journal of Econometrics.

McAleer, M. and B. da Veiga (2007), Forecasting Value-at-Risk with a parsimonious portfolio spillover GARCH (PS-GARCH) Model, Unpublished paper, School of Economics and Commerce, University of Western Australia.

Odier, P. and B. Solnik (1993), Lessons for international asset allocation, Financial Analysts Journal, March/April, 63-77.

De Santis, G. and B. Gerard (1997), International asset pricing and portfolio diversification with time-varying risk, Journal of Finance, 52, 1881-1912.

Solnik, B., C. Boucrelle and Y.L. Fur (1996), International market correlation and volatility, Financial Analysts Journal, 52(5), 17-34.

Wainscott, C.B. (1990), The stock-bond correlation and its implications for asset allocation, Financial Analysts Journal, 46(4), 55-79.

\section{ACKNOWLEDGEMENTS}

The first author acknowledges the financial support of the Indonesian Islamic University and the Australian Research Council. The second author wishes to thank the financial support of the Australian Research Council. The authors would like to thank Felix Chan for assistance with the computer programs and many helpful discussions. 
APPENDIX: Figures 1-15 are the forecasts of conditional correlations between pair of assets resulted from the CCC, VARMA-AGARCH and VARMA-GARCH models.

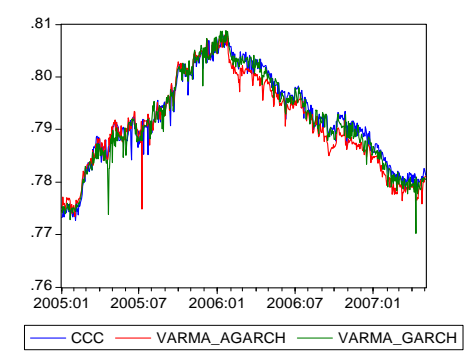

Figure 1. Ausbond-Nzbond

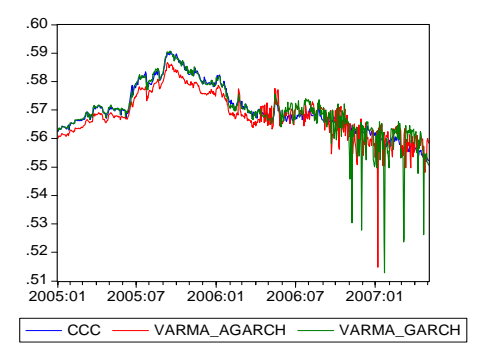

Figure 2. Ausbond-Ausstock

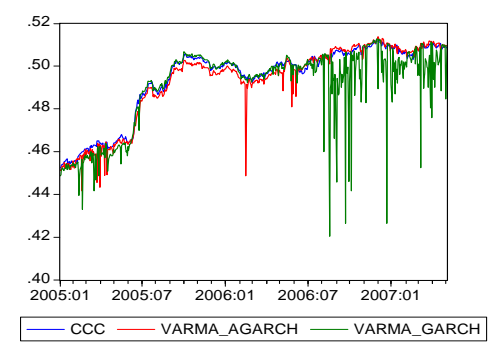

Figure 3. Ausbond-Nzsstock

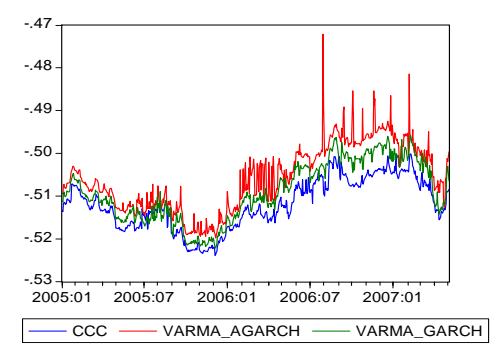

Figure 4. Ausbond-Usdaud

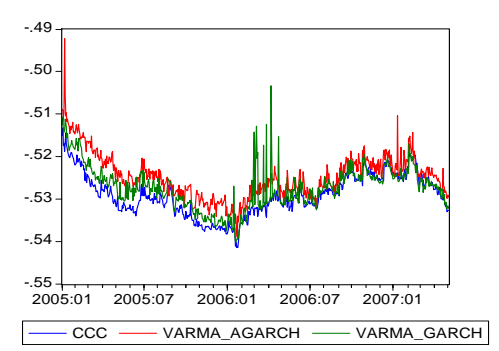

Figure 5. Ausbond-Usdnzd

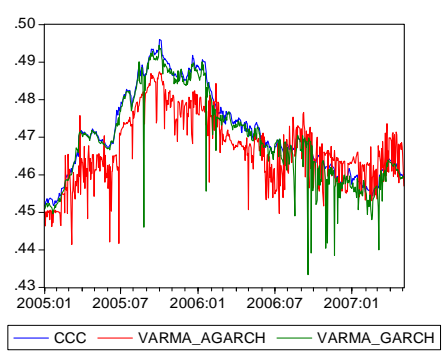

Figure 6. Nzbond-Ausstock

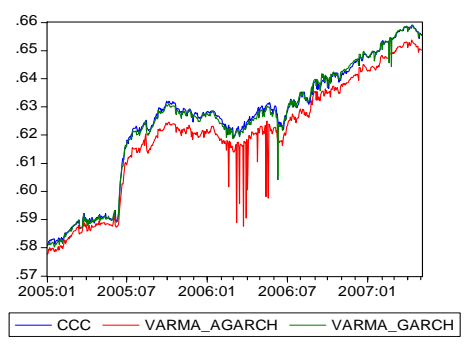

Figure 7. Nzbond-Nzstock

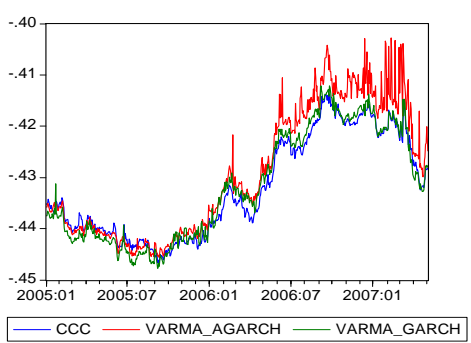

Figure 8. Nzbond-Usdaud

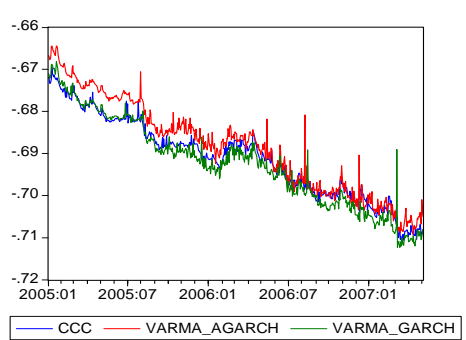

Figure 9. Nzbond-Usdnzd

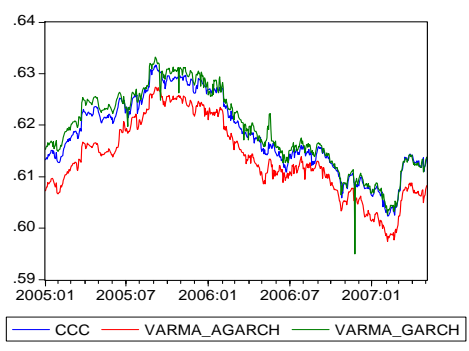

Figure10. Ausstock-Nzstock

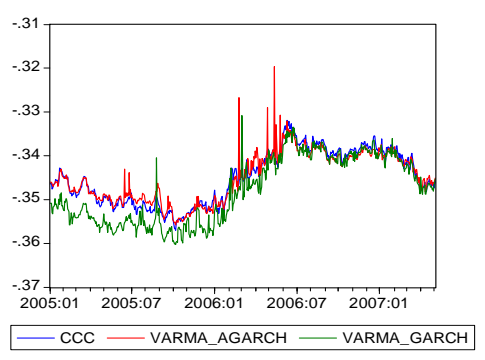

Figure 11. Ausstock-Usdaud

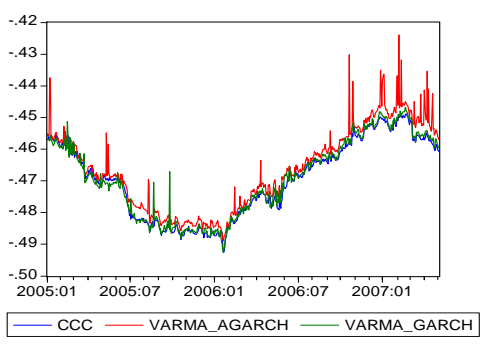

Figure 12. Ausstock-Usdnzd

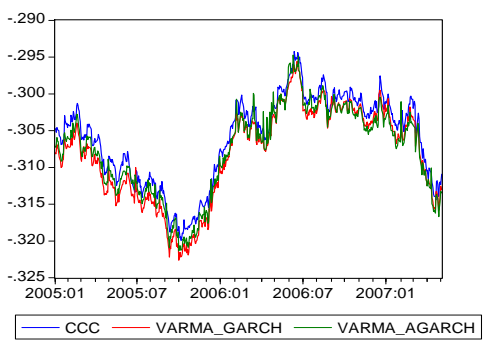

Figure 13. Nzstock-Usdaud

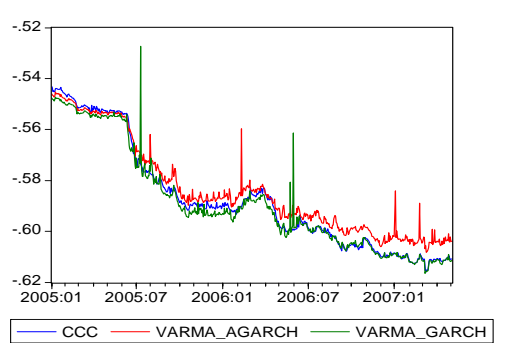

Figure 14. Nzstock-Usdnzd

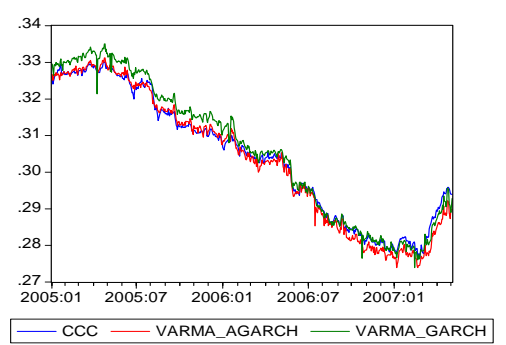

Figure 15. Usdaud-Usdnzd 